\title{
Robust Optimization Design of Spindle Box Based on Kriging Model
}

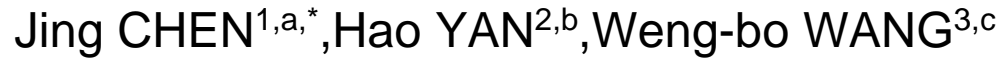 \\ ${ }^{1}$ Guangxi Scientific Experiment Center of Mining, Metallurgy and Environment, Guilin University of \\ Technology, Guilin 541004, CHN; \\ ${ }^{2}$ School of Mechanical and Control Engineering, Guilin University of Technology, Guilin 541004, \\ $\mathrm{CHN}$ \\ ${ }^{3}$ School of Mechanical and Control Engineering, Guilin University of Technology, Guilin 541004, \\ $\mathrm{CHN}$ \\ ajingc812@163.com, b287770311@qq.com, c251661096@qq.com
}

Key words: spindle box, interval analysis, robust optimization, Kriging model.

Abstract. To improve the static and dynamic performance of the machine tool spindle box and its robustness, the interval model is used to describe the uncertainty of the spindle box. The optimization model of the main spindle box is established considering the uncertainty of design parameters. By using the Latin square test design method, the spindle box will be in the process of static and dynamic characteristic finite element simulation test. The static and dynamic characteristics of the spindle box are fitted by Kriging model. The non-probabilistic robust optimization design method based on Kriging model is used to optimize the design of the spindle box, and the results are verified by finite element analysis.

\section{Introduction}

The machine tool spindle box is one of the important parts to ensure the accuracy of the machine. Make the static and dynamic analysis and optimization of the structure of the machine tool spindle box, so as to improve the static and dynamic performance of the machine, and then improve the machining accuracy of the machine tool [1]. Robust optimal design is aims to reduce the sensitivity of the performance to the uncertainty at the same time. It has been widely used in engineering design. Therefore, considering uncertainty of the robust optimization design of machine tool spindle box, greatly improve the machine tool spindle box structure of the static and dynamic performance and robustness, is of great significance for improving the performance of the machine tool.

There is no explicit functional relationship between the performance and the design variables of complex engineering problems. The response surface method was used to construct the approximate model [3]. Document [4] using Kriging model to get the stiffness and approximate expressions between design variables. According to the principle of analytical robust design, the robust design of the spindle box of CNC gear hobbing machine is carried out in [5]. But in fact, the system functions in the design range of design parameters must be continuous and high order derivative.

In document [2], a non probabilistic robust optimization design model based on interval analysis is proposed, which does not need to know the probability distribution function of the design parameters, nor does it require that the objective function and the constraints are continuous and differentiable. The application of interval analysis in engineering more and more widely [6].

In this paper, the Latin square test design method is used to simulate the static and dynamic characteristics of the spindle box of a machining center. The Kriging model is used to fit the approximate model of the static and dynamic characteristics of the spindle box, and the non probabilistic robust optimization design method based on interval analysis is applied to the robust optimization design of the spindle box. The results of the robust optimization design of the spindle box are verified by using finite element analysis. 


\section{2 non-probabilistic robust optimization design based on interval analysis}

The upper bound and lower bound of the objective function and the constraints are obtained by using the interval analysis algorithm. The deterministic transformation of interval number optimization model based on the method of interval number ordered permutation and the method of interval order based on degree [2].

\section{1 optimization model}

Interval model is used to describe uncertainty, The optimization model with uncertain factors:

$$
\begin{array}{ll}
\min & f(\boldsymbol{X}, \boldsymbol{Y}) \\
\text { s.t. } & g_{i}(\boldsymbol{X}, \boldsymbol{Y}) \leq 0 ; \quad i=1,2, \cdots, n \\
& h_{j}(\boldsymbol{X}, \boldsymbol{Y})=0 ; \quad j=1,2, \cdots, m \\
& {\left[\boldsymbol{X}+\Delta \boldsymbol{X}_{1}, \boldsymbol{X}+\Delta \boldsymbol{X}_{2}\right] \subset\left[\boldsymbol{X}_{\text {min }}, \boldsymbol{X}_{\text {max }}\right] .}
\end{array}
$$

$f$ is the optimization goal; $\boldsymbol{X}=\left(x_{1}, x_{2}, \cdots, x_{k}\right)$ is design variable vector; $\boldsymbol{Y}=\left(y_{1}, y_{2}, \cdots, y_{t}\right)$ is the design parameter vector. $g_{i}$ is an inequality constraint, $n$ is the number of inequality constraints; $h_{j}$ is equality constraint, $m$ is the number of equality constraints. $\Delta \boldsymbol{X}_{1}$ and $\Delta \boldsymbol{X}_{2}$ are the upper and lower bounds of the design variables $\boldsymbol{X} . \boldsymbol{X}_{\max }$ and $\boldsymbol{X}_{\min }$ are the upper and lower bounds of the design variables.

\subsection{Robustness and deterministic transformation of objective function}

The minimum value of the interval function can be transformed into the minimum mean value and the minimum fluctuation amplitude. At the same time, the uncertain objective function is transformed into certainty.

$$
\min f(\boldsymbol{X}, \boldsymbol{Y})=\lambda F^{c}\left(\boldsymbol{X}, \boldsymbol{Y}^{I}\right)+(1-\lambda) F^{r}\left(\boldsymbol{X}, \boldsymbol{Y}^{I}\right) .
$$

$\lambda$ is the weight coefficient, $0 \leq \lambda \leq 1 . Y^{I}$ is the design parameter vector, and its uncertainty is represented by interval numbers.

\subsection{Robustness and deterministic transformation of inequality constraints}

When the uncertain variables are described by interval numbers, the original constraint function $g_{i}(\boldsymbol{X}, \boldsymbol{Y})$ is changed into the corresponding interval constraint function $G_{i}\left(\boldsymbol{X}, \boldsymbol{Y}^{I}\right)$. When the robustness index of inequality constraint is $\varphi_{i}$, the inequality constraints in formula (1) can be transformed into

$$
P_{G_{i}\left(X, Y^{I}\right) \leq 0} \geq \varphi_{i} .
$$

$P_{G_{i}\left(X, Y^{I}\right) \leq 0}$ is the percentage of $G_{i}\left(X, Y^{I}\right)$ less than or equal to the interval number 0.

\section{Robust optimization design of spindle box based on Kriging model}

\subsection{Optimization model of spindle box with uncertain factors}

In this paper, the robust optimization design of the spindle box of a machining center is carried out. The cross section of the spindle box is shown in Figure 1. 


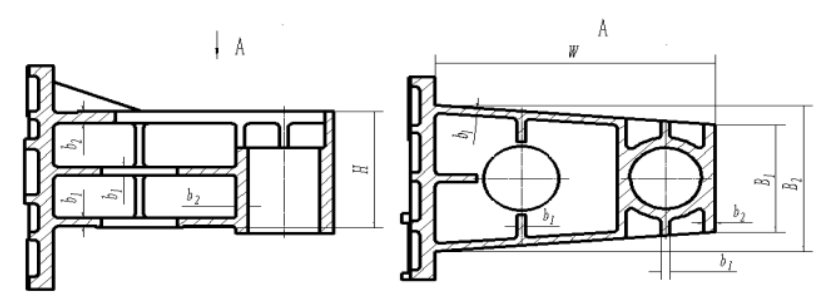

Figure 1.Cross section of spindle box

The objective of the optimization is that the quality of the spindle box is the lowest, the static stiffness is the largest, and the natural frequency of the first order is the largest.

The structural dimensions shown in Figure 1 are used as design variables. The design variables and the design parameter of the spindle box are shown in table 1.

Table 1.Design variables of spindle box

\begin{tabular}{|c|c|c|c||c|c|c|c|}
\hline $\begin{array}{c}\text { Design } \\
\text { variables }\end{array}$ & Symbol & $\begin{array}{c}\text { Initial } \\
\text { value }\end{array}$ & $\begin{array}{c}\text { Upper and } \\
\text { lower bounds }\end{array}$ & $\begin{array}{c}\text { Design } \\
\text { variables }\end{array}$ & Symbol & Initial value & $\begin{array}{c}\text { Upper and } \\
\text { lower bounds }\end{array}$ \\
\hline Box Width & $W / m m$ & 588 & {$[548,628]$} & Box length & $B_{2} / m m$ & 358 & {$[328,388]$} \\
\hline box Height & $H / m m$ & 285 & {$[265,305]$} & $\begin{array}{c}\text { Thickness of } \\
\text { rib plate }\end{array}$ & $b_{1} / \mathrm{mm}$ & 18 & {$[14,22]$} \\
\hline Box length & $B_{1} / \mathrm{mm}$ & 265 & {$[245,285]$} & $\begin{array}{c}\text { Thickness of } \\
\text { rib plate }\end{array}$ & $b_{2} / \mathrm{mm}$ & 25 & {$[20,30]$} \\
\hline
\end{tabular}

The design parameter of the spindle box is the elastic modulus of the material, which is an uncertain variable $E / M P a$, initial value is $1.3 \times 10^{5}$, and Upper and lower bounds are $\left[1.2805 \times 10^{5}, 1.3195 \times 10^{5}\right]$. The main objective is to minimize the axial deformation of the spindle box.The radial deformation of the main axle box, $\delta_{y}$, is less than $1.0 \times 10^{-5} \mathrm{~m}$. First order natural frequency, $f$, is not less than $280 \mathrm{~Hz}$. Mass, $m$, is less than or equal to $250 \mathrm{~kg}$. The optimization model of spindle box is established.

$$
\begin{aligned}
\min & f(\boldsymbol{X}, \boldsymbol{Y})=\min \delta_{z} \\
\text { s.t. } & g_{1}(\boldsymbol{X}, \boldsymbol{Y})=\delta_{y}<1.0 \times 10^{-5} \\
& g_{2}(\boldsymbol{X}, \boldsymbol{Y})=f \geq 280 \\
& g_{3}(\boldsymbol{X}, \boldsymbol{Y})=m \leq 250 \\
& {\left[\boldsymbol{X}+\Delta \boldsymbol{X}_{1}, \boldsymbol{X}+\Delta \boldsymbol{X}_{2}\right] \subset\left[\boldsymbol{X}_{\min }, \boldsymbol{X}_{\max }\right] . } \\
\boldsymbol{X}= & \left(x_{1}, x_{2}, x_{3}, x_{4}, x_{5}, x_{6}\right)=\left(W, H, B_{1}, B_{2}, b_{1}, b_{2}\right) \text { is a vector of design variables. } \boldsymbol{Y}=\left(y_{1}\right)=(E) \text { is the interval }
\end{aligned}
$$
vector of design parameters. Its value is shown in Table 2. The value of $\boldsymbol{X}_{\max }$ and $\boldsymbol{X}_{\min }$ are shown in Table 1. Lower deviation and upper deviation are obtained from the standard of value and tolerance.

\subsection{Kriging model of the main spindle box}

Based on the basic idea of robust optimization design based on interval analysis, a double nested optimization problem is obtained. The Kriging modeling technique can provide the best unbiased prediction method. This is the basic process of constructing the Kriging model of the headstock.

Latin hypercube design:the Latin hypercube sampling procedure was used to sample the design variables and design parameters, and 40 groups of samples were obtained.

Finite element simulation test of spindle box:spindle box material density is $7.3 \times 10^{3} \mathrm{~kg} / \mathrm{m}^{3}$, Poisson's ratio is 0.25 . Parameterized modeling with SolidWorks parametric plug-in. The axial deformation, radial deformation, first order mode and two order mode of the spindle box are shown in Figure 2. 


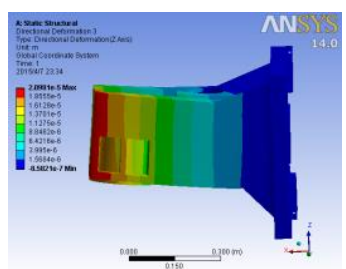

(a)axial deformation

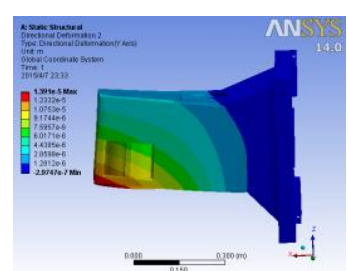

(b)radial deformation

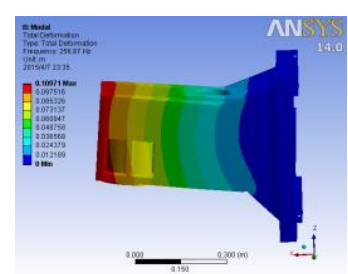

(c)first order mode

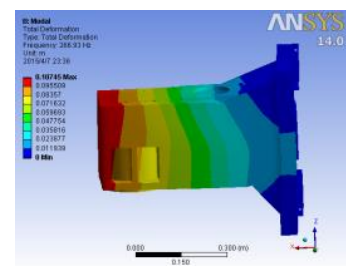

(d)two order mode

Figure 2. Finite element static and dynamic simulation test of spindle box

\subsection{Robust optimization design of spindle box based on Kriging model}

Firstly, the objective function and constraint function of the optimization model of spindle box are transformed into deterministic. Then, the robust optimization design is divided into two stages: continuous design variables robust optimization, discrete design variables robust optimization. Then, The problem of robust optimization for spindle box in the MATLAB. Finally, the ANSYS software is used to carry out the finite element analysis of the robust optimization value, and the results of the robust optimization design of the spindle box are verified. The results are shown in Table 2 .

Table 2. Robust optimization design results and finite element analysis of spindle box

\begin{tabular}{|c|c|c|c|c|c|c|c|}
\hline & Symbol & $\begin{array}{l}\text { Optimal } \\
\text { value }\end{array}$ & $\begin{array}{l}\text { Finite element } \\
\text { analysis }\end{array}$ & error & & Symbol & $\begin{array}{l}\text { Optimal } \\
\text { value }\end{array}$ \\
\hline $\begin{array}{l}\text { Optimization } \\
\text { goal }\end{array}$ & $\delta_{z} / 10^{5} \mathrm{~m}$ & 1.1 & 1.12 & $1.82 \%$ & \multirow{6}{*}{$\begin{array}{c}\text { design } \\
\text { variables }\end{array}$} & $W / m m$ & $598_{-0.8}^{+0.8}$ \\
\hline \multirow{3}{*}{$\begin{array}{l}\text { constraint } \\
\text { condition }\end{array}$} & $\delta_{y} / 10^{5} \mathrm{~m}$ & 1.0 & 1.08 & $8 \%$ & & $\mathrm{H} / \mathrm{mm}$ & $305_{-0.5}^{+0.5}$ \\
\hline & $f / H z$ & 296 & 290.26 & $-1.94 \%$ & & $B_{1} / \mathrm{mm}$ & $285_{-0.5}^{+0.5}$ \\
\hline & $\mathrm{m} / \mathrm{kg}$ & 244 & 251.37 & $3.02 \%$ & & $B_{2} / \mathrm{mm}$ & $378_{-0.5}^{+0.5}$ \\
\hline & & & & & & $b_{1} / m m$ & $20_{-0.1}^{+0.1}$ \\
\hline & & & & & & $b_{2} / \mathrm{mm}$ & $30_{-0.1}^{+0.1}$ \\
\hline
\end{tabular}

The axial deformation, the first natural frequency, the mass error is $1.82 \%,-1.94 \%$, and $3.02 \%$. The error is small. Therefore, the robust optimization design of spindle box based on interval analysis is feasible.

\section{Conclusion}

Considering the uncertainty of the design parameters, the optimization model of the spindle box is established. Based on the Kriging model, the functional relationship between the characteristics of the headstock and the design variables and design parameters is established. The Non probabilistic robust optimization design based on interval analysis method is used to optimize the design of the spindle box. The results of finite element analysis show that the robust optimization design of spindle box based on Kriging model is feasible. Spindle box interval analysis of robust optimization design does not require the objective function is continuous and based on high order derivative, it has certain engineering adaptability.

\section{References}

[1] Fengtao Wei, Jianfeng Zhao, Song Li, Finite element analysis and optimal design based on ANSYS in XH2408 gantry style NC machining center, International Journal of Plant Engineering and Management, vol.15, pp. 188-192, 2010.

[2] Rongmei Dong, Wei Sun, Huanwei Xu, Non probabilistic robust optimization design based on interval analysis, journal of dalian university of technology, vol.51, pp. 51-55, 2011. 
[3] Fengtao Wei, Li Song, Yan Li, Multi objective optimization design of spindle box based on ISIGHT platform, manufacturing technology and machine tool, pp. 97-101,2015.

[4] Yongliang Chen, Shuang Liu, Hantao Wang, Jian Zhang, Peihua Gu, Robust design of spindle box based on Kriging agent model, Journal of Tianjin University, vol.44, pp. 1111-1116, 2011.

[5] Zhang Jian, Bao Nengsheng, Bao Guojun, et al. Analytical approach to robust design of nonlinear mechanical systems, Frontiers of Mechanical Engineering in China,vol.4, pp. 203-214, 2009.

[6] Jianping Fan, Xuyong Chen, Structural Robust Optimization Design Based on interval model, Journal of solid mechanics, vol.3, pp. 539-544, 2014. 